\title{
Intravascular ultrasound as an adjunct tool for angiographically intermediate lesions and complex coronary interventions: patient selection and perspectives
}

\author{
This article was published in the following Dove Press journal: \\ Journal of Vascular Diagnostics \\ 23 November 2015 \\ Number of times this article has been viewed
}

\begin{abstract}
Eui $\operatorname{Im}^{1}$
Jung-Sun $\mathrm{Kim}^{2,3}$

Myeong-Ki Hong $2-4$

'Division of Cardiology, Yongin

Severance Hospital, Yonsei University Health System, Yongin, ${ }^{2}$ Division of

Cardiology, Severance Cardiovascular Hospital, Yonsei University Health System, ${ }^{3}$ Cardiovascular Research Institute, ${ }^{4}$ Severance Biomedical Science Institute, Yonsei University College of Medicine, Seoul, Korea
\end{abstract}

Correspondence: Myeong-Ki Hong Division of Cardiology, Severance Cardiovascular Hospital,Yonsei University Health System, Yonsei University College of Medicine, 250 Seongsanno, Seodaemun-gu, Seoul 120-752, Korea

Tel +82 222288458

Fax +82 23932 04I

Email mkhong6I@yuhs.ac

\begin{abstract}
Intravascular ultrasound (IVUS) provides valuable anatomic information about the coronary arterial lumen, wall, and plaques that cannot be assessed by coronary angiography alone. For over 2 decades, IVUS has been shown to be a helpful tool for identifying significant ischemia in angiographically intermediate left main (LM) or non-LM lesions by measuring the minimum luminal area. It can also guide percutaneous coronary intervention (PCI) in complex coronary lesions such as LM, bifurcation, chronic total occlusion, in-stent restenosis, and long or calcified lesions. In these complex lesions, IVUS can reduce stent thrombosis or restenosis by accurate lesion assessment and detection of stent underexpansion, malapposition, or edge dissections. Through further intervention based on these IVUS findings, optimal stent deployment can be achieved. IVUS can also identify the culprit lesion with plaque rupture, and vulnerable lesions with a large plaque burden or thin-cap fibroatheroma. Although other new imaging modalities with improved resolution and technologies are attracting increased clinical attention, IVUS remains the most reliable intracoronary imaging modality to guide PCI until other new imaging devices are proven to be useful and improve clinical outcomes. However, current data on clinical utility are conflicting and the guidelines do not recommend routine use of IVUS when performing angiography or PCI. In this review, we focus on issues related to the selection of patients who might benefit from IVUS guidance and discuss future perspectives on intracoronary imaging.
\end{abstract}

Keywords: intravascular ultrasound, angiography, coronary artery disease

\section{Introduction}

Coronary angiography is still the gold standard for the diagnosis of coronary artery disease. However, two-dimensional angiography has inherent limitations such as vessel overlap or possible foreshortening, which can cause a misdiagnosis of disease severity. ${ }^{1}$

Intravascular ultrasound (IVUS) is a catheter-based imaging modality that provides cross-sectional images of the coronary artery, enabling measurement of luminal and vessel areas. ${ }^{2}$ When it was first developed in the 1970 s, the initial role of IVUS was to evaluate plaques in atherosclerotic coronary arteries. ${ }^{3}$ With the development of automatic lesion analysis software and enhanced imaging of metallic stent struts, the application of IVUS was further extended to guide successful coronary stent implantation. ${ }^{3}$ Currently, IVUS can accurately identify plaque burden, morphology, and characteristics. As IVUS quantification of coronary stenosis has fewer anatomic limitations than 
angiography, it can be especially useful when angiographic diameter stenosis is considered indeterminate or unreliable. ${ }^{4}$ However, the most important role of IVUS in current clinical practice might be as an adjunct when performing percutaneous coronary intervention (PCI). IVUS is a very useful tool for lesion assessment before PCI in complex cases such as left main (LM) stenosis, calcified lesions, or bifurcations. ${ }^{5}$ IVUS is also helpful during PCI to evaluate stent sizing, expansion, apposition, and edge dissection. ${ }^{3}$ After PCI, it can be used to determine the cause of stent failure, including in-stent restenosis and stent thrombosis (ST). ${ }^{6}$

Most experts agree that IVUS guidance improves the quality and outcomes of PCI. In many studies, IVUS-guided PCI has been shown to be associated with lower rates of adverse clinical events compared with angiography-guided PCI. ${ }^{7-10}$ However, there are also controversial data regarding the benefit of IVUS guidance with respect to clinical outcomes. ${ }^{11-15}$ Clinical studies evaluating the utility of IVUS are described in Table 1 . There are two possible explanations for why angiography-guided PCI achieves similar clinical outcomes to IVUS-guided PCI. First, IVUS has significantly increased our understanding of the mechanisms of stent failure and poor outcomes. As a result, most operators usually perform sufficient lesion preparation and postdilation to minimize stent underexpansion or malapposition. These procedures are now possible without IVUS guidance. Second, the improved performance of newer generation drug-eluting stents (DESs) may have reduced the impact of IVUS guidance on clinical outcomes.

In this context, both American and European guidelines similarly acknowledge the benefit of IVUS in selected cases only, such as LM or stent failure lesions. ${ }^{16,17}$ These current guidelines do not recommend routine IVUS for lesion

Table I Studies comparing outcomes between IVUS-guided and angiography-guided PCI

\begin{tabular}{|c|c|c|c|c|c|c|c|}
\hline Study & Design & $\begin{array}{l}\text { N (IVUS vs } \\
\text { angiography) }\end{array}$ & Inclusion & $\begin{array}{l}\text { Follow-up, } \\
\text { months }\end{array}$ & Outcome measure & $\begin{array}{l}\text { Results (IVUS vs } \\
\text { angiography) }\end{array}$ & $P$-value \\
\hline Kim et al" & RCT & 269 vs 274 & $\begin{array}{l}\text { Long lesions } \\
\text { (stents } \geq 28 \mathrm{~mm} \text { ) }\end{array}$ & 12 & $\begin{array}{l}\text { Composite of } \\
\text { cardiovascular } \\
\text { death, ST, MI, TVR }\end{array}$ & $\begin{array}{l}4.5 \% \text { vs } 7.3 \% \\
4.0 \% \text { vs } 8.1 \% *\end{array}$ & $\begin{array}{l}\text { NS } \\
P=0.048 *\end{array}$ \\
\hline Jakabcin et $\mathrm{al}^{12}$ & RCT & 105 vs 105 & Complex cases & 18 & $\begin{array}{l}\text { Composite of } \\
\text { death, MI, TVR }\end{array}$ & $11 \%$ vs $12 \%$ & NS \\
\hline Chieffo et $\mathrm{al}^{15}$ & RCT & I 42 vs 142 & Complex lesions & 24 & $\begin{array}{l}\text { Composite of cardiac } \\
\text { death, MI, TVR }\end{array}$ & $16.9 \%$ vs $23.2 \%$ & NS \\
\hline $\begin{array}{l}\text { Witzenbichler } \\
\text { et } \mathrm{al}^{7}\end{array}$ & Observational & 3,349 vs 5,234 & All comers & 12 & $\begin{array}{l}\text { Definite/probable } \\
\text { ST, MI } \\
\text { Composite of } \\
\text { cardiac death, ST, MI }\end{array}$ & $\begin{array}{l}0.6 \% \text { vs } 1.0 \% \\
2.5 \% \text { vs } 3.7 \% \\
3.1 \% \text { vs } 4.7 \%\end{array}$ & $\begin{array}{l}P=0.02 \\
P=0.002 \\
P<0.001\end{array}$ \\
\hline Roy et $\mathrm{al}^{10}$ & Observational & $\begin{array}{l}884 \text { vs } 884 \\
\text { by matching }\end{array}$ & All comers & 12 & Definite ST & $0.7 \%$ vs $2.0 \%$ & $P=0.014$ \\
\hline Park et al ${ }^{13}$ & Observational & $\begin{array}{l}463 \text { vs } 463 \\
\text { by matching }\end{array}$ & Nearly all comers & 12 & $\begin{array}{l}\text { Composite of cardiac } \\
\text { death, MI, TLR }\end{array}$ & $4.3 \%$ vs $2.4 \%$ & $P=0.047$ \\
\hline Youn et $\mathrm{al}^{1 / 4}$ & Observational & 125 vs 216 & Primary $\mathrm{PCl}$ cases & 36 & $\begin{array}{l}\text { Composite of } \\
\text { death, MI, TLR, TVR }\end{array}$ & $12.8 \%$ vs $18.1 \%$ & NS \\
\hline Kim et $\mathrm{al}^{37}$ & Observational & $\begin{array}{l}487 \text { vs } 487 \\
\text { by matching }\end{array}$ & $\begin{array}{l}\text { Non-left main } \\
\text { bifurcation lesions }\end{array}$ & 36 & Death or MI & $3.8 \%$ vs $7.8 \%$ & $P=0.03$ \\
\hline Hong et $\mathrm{al}^{40}$ & Observational & $\begin{array}{l}201 \text { vs } 201 \\
\text { by matching }\end{array}$ & $\begin{array}{l}\text { Chronic total } \\
\text { occlusion lesions }\end{array}$ & 24 & $\begin{array}{l}\text { Definite/probable } \\
\text { ST, MI }\end{array}$ & $\begin{array}{l}0 \% \text { vs } 3.0 \% \\
1.0 \% \text { vs } 4.0 \%\end{array}$ & $\begin{array}{l}P=0.014 \\
P=0.058\end{array}$ \\
\hline Jang et $\mathrm{al}^{8}$ & Meta-analysis & $\begin{array}{l}11,793 \text { vs } \\
13,056\end{array}$ & $\begin{array}{l}3 \text { RCT I2 } \\
\text { observational } \\
\text { studies }\end{array}$ & $\begin{array}{l}\text { Not } \\
\text { applicable }\end{array}$ & $\begin{array}{l}\text { Death } \\
\text { Definite/probable ST } \\
\text { MI } \\
\text { TVR }\end{array}$ & $\begin{array}{l}\text { OR } 0.64 ; 95 \% \text { Cl } 0.5 \mathrm{I}-0.8 \mathrm{I} \\
\text { OR } 0.59 ; 95 \% \mathrm{Cl} 0.42-0.82 \\
\text { OR } 0.57 ; 95 \% \mathrm{Cl} 0.42-0.78 \\
\text { OR } 0.8 \mathrm{I} ; 95 \% \mathrm{Cl} 0.68-0.95\end{array}$ & $\begin{array}{l}P<0.001 \\
P=0.002 \\
P<0.001 \\
P=0.01\end{array}$ \\
\hline Ahn et $\mathrm{al}^{9}$ & Meta-analysis & $\begin{array}{l}12,499 \text { vs } \\
14,004\end{array}$ & $\begin{array}{l}3 \text { RCT I4 } \\
\text { observational } \\
\text { studies }\end{array}$ & $\begin{array}{l}\text { Not } \\
\text { applicable }\end{array}$ & $\begin{array}{l}\text { Death } \\
\text { Definite/probable ST } \\
\text { MI } \\
\text { TVR }\end{array}$ & $\begin{array}{l}\text { OR } 0.61 ; 95 \% \mathrm{Cl} 0.48-0.79 \\
\text { OR } 0.59 ; 95 \% \mathrm{Cl} 0.47-0.75 \\
\text { OR } 0.57 ; 95 \% \mathrm{Cl} 0.44-0.75 \\
\text { OR } 0.8 \mathrm{I} ; 95 \% \mathrm{Cl} 0.66-1.00\end{array}$ & $\begin{array}{l}P<0.001 \\
P<0.001 \\
P<0.001 \\
P=0.046\end{array}$ \\
\hline $\begin{array}{l}\text { de la Torre } \\
\text { Hernandez } \\
\text { et } \mathrm{al}^{35}\end{array}$ & Meta-analysis & $\begin{array}{l}505 \text { vs } 505 \\
\text { by matching }\end{array}$ & $\begin{array}{l}4 \text { observational } \\
\text { studies on left } \\
\text { main lesions }\end{array}$ & 36 & $\begin{array}{l}\text { Composite of cardiac } \\
\text { death, MI, TLR } \\
\text { Definite/probable ST }\end{array}$ & $\begin{array}{l}11.3 \% \text { vs } 16.4 \% \\
0.6 \% \text { vs } 2.2 \%\end{array}$ & $\begin{array}{l}P=0.04 \\
P=0.04\end{array}$ \\
\hline
\end{tabular}

Note: *Result from per-protocol analysis.

Abbreviations: IVUS, intravascular ultrasound; PCI, percutaneous coronary intervention; RCT, randomized control trial; ST, stent thrombosis; MI, myocardial infarction; TVR, target vessel revascularization; NS, not significant; TLR, target lesion revascularization; OR, odds ratio; Cl, confidence interval. 
assessment when revascularization is not being contemplated. Therefore, judicious selection of patients who can benefit from IVUS-guided PCI is very important in clinical practice. Although several reviews have addressed the roles or advantages of IVUS, few of them specifically address the appropriate patient groups for IVUS evaluation. In this review, we focus on the issues related to patient selection for IVUS-guided PCI and the future perspectives of intracoronary imaging.

\section{Angiographically intermediate lesions}

Fractional flow reserve (FFR) is the gold standard for the assessment of functional significance in angiographically intermediate lesions. ${ }^{18}$ Although positive predictive values of IVUS measurements were not satisfactory for the identification of ischemia, there have been many attempts to correlate IVUS measurements with the functional significance of stenotic lesions. ${ }^{19}$

\section{Left main lesions}

IVUS measurements demonstrated a relatively strong correlation with FFR when evaluating intermediate LM lesions. The limited variability of LM coronary artery length, diameter, and the amount of supplied myocardium explains the better correlation for LM lesions compared to non-LM lesions. ${ }^{4}$ The most widely used parameter is the minimum luminal area (MLA). Jasti et al showed that MLA $<5.9 \mathrm{~mm}^{2}$ and minimum luminal diameter $<2.8 \mathrm{~mm}$ correlated well with FFR $<0.75$ with a sensitivity and specificity $>90 \%$ (Table 2 ). ${ }^{20}$ This MLA value was prospectively tested in the LITRO study. ${ }^{21}$ PCI was deferred in $96 \%(179 / 186)$ of patients with MLA $\geq 6.0 \mathrm{~mm}^{2}$ and only eight $(4.5 \%)$ patients in the deferred group required subsequent LM revascularization during a 2-year follow-up. None of the patients in that study suffered myocardial infarction. Thus, it is safe to defer PCI for intermediate LM lesions with $\mathrm{MLA} \geq 6.0 \mathrm{~mm}^{2}$. In the Asian population with smaller normal coronary diameters, an MLA cutoff $\leq 4.5 \mathrm{~mm}^{2}$ correlates with FFR $\leq 0.8 .^{22,23}$ Recently, the Society of Cardiovascular Angiography and Interventions released an expert consensus statement regarding IVUS in LM disease. Experts recommend that IVUS can be used to appraise the significance of LM stenosis, employing a cutoff MLA of $6 \mathrm{~mm}^{2}$ to assess whether revascularization is warranted. ${ }^{4}$ Currently, IVUS is a class IIa recommendation in the assessment of angiographically indeterminant LM lesions. ${ }^{16,17}$

\section{Non-left main lesions}

One limitation of an IVUS MLA for predicting the hemodynamic significance of intermediate non-LM lesions is that the functional effects of non-LM lesions are dependent on additional factors besides MLA. ${ }^{4}$ These factors include lesion location in the coronary tree, lesion length, eccentricity, entrance and exit angle, shear forces, reference vessel diameters, and the amount of viable myocardium subtended by the lesion. ${ }^{24}$ Many investigators have tried to establish a reliable IVUS MLA cutoff value in intermediate non-LM lesions, by which operators can confidently perform ischemia-driven PCI. However, there is variation in the MLA cutoff values derived from many studies (Table 2). ${ }^{25-28}$ FIRST was a multicenter prospective registry study of patients who had intermediate non-LM stenosis $(40 \%-80 \%)$ on angiography. Although an IVUS MLA $<3.07 \mathrm{~mm}^{2}$ was the best cutoff value for FFR $<0.8$, its sensitivity and specificity were low (64\% and $65 \%$, respectively). ${ }^{28}$ The correlation between IVUS and FFR values is weak in demonstrating significant lesions, and their correlation is best for demonstrating nonsignificant lesions. ${ }^{29}$ When considering the combined results of many IVUS/FFR correlation studies, an MLA $\geq 4.0 \mathrm{~mm}^{2}$ has reasonable accuracy in identifying nonsignificant lesions for which PCI can be safely deferred. ${ }^{4,5}$ However, FFR remains the gold standard for confirming the functional significance of intermediate non-LM lesions if MLA is $<4.0 \mathrm{~mm}^{2}$. Experts agree that IVUS measurements for the determination of non-LM lesion

Table 2 Studies correlating IVUS with FFR to identify functionally significant lesions

\begin{tabular}{|c|c|c|c|c|c|c|}
\hline Lesion subset & Study & $\mathbf{N}$ & Angiographic DS\% & FFR & IVUS parameters & Reliability \\
\hline \multirow[t]{5}{*}{ Left main lesions } & Jasti et $\mathrm{al}^{20}$ & 55 & Not defined & $<0.75$ & MLA $<5.9 \mathrm{~mm}^{2}$ & Sensitivity $93 \%$, specificity $95 \%$ \\
\hline & & & & & MLD $<2.8 \mathrm{~mm}$ & Sensitivity $93 \%$, specificity $98 \%$ \\
\hline & Kang et $\mathrm{al}^{23}$ & 55 & $30-80$ & $<0.75$ & $\mathrm{MLA}<4.1 \mathrm{~mm}^{2}$ & Sensitivity $95 \%$, specificity $83 \%$ \\
\hline & & & & $<0.80$ & $M L A<4.8 \mathrm{~mm}^{2}$ & Sensitivity $89 \%$, specificity $83 \%$ \\
\hline & Park et $\mathrm{al}^{22}$ & 112 & $30-80$ & $\leq 0.80$ & $M L A \leq 4.5 \mathrm{~mm}^{2}$ & Sensitivity $77 \%$, specificity $82 \%$ \\
\hline \multirow[t]{4}{*}{ Non-left main lesions } & Lee et $\mathrm{al}^{27}$ & 94 & $30-75$ & $<0.75$ & $M L A \leq 2.0 \mathrm{~mm}^{2}$ & Sensitivity $82 \%$, specificity $81 \%$ \\
\hline & Kang et $\mathrm{al}^{25}$ & 201 & $30-75$ & $<0.80$ & $\mathrm{MLA}<2.4 \mathrm{~mm}^{2}$ & Sensitivity $90 \%$, specificity $60 \%$ \\
\hline & Waksman et $\mathrm{al}^{28}$ & 350 & $40-80$ & $<0.80$ & $\mathrm{MLA}<3.07 \mathrm{~mm}^{2}$ & Sensitivity $64 \%$, specificity $65 \%$ \\
\hline & Briguori et $\mathrm{al}^{26}$ & 53 & $40-70$ & $<0.75$ & $M L A \leq 4.0 \mathrm{~mm}^{2}$ & Sensitivity $92 \%$, specificity $56 \%$ \\
\hline
\end{tabular}

Abbreviations: IVUS, intravascular ultrasound; FFR, fractional flow reserve; DS, diameter stenosis; MLA, minimum luminal area; MLD, minimum luminal diameter. 
severity should not be relied on for revascularization in the absence of additional functional evidence. ${ }^{4}$

\section{Left main stenting}

Undoubtedly, LM stenosis is the most critical subset of coronary disease. Given the potential disastrous consequences of procedural failure resulting in ST or restenosis, IVUS-guided PCI should be strongly recommended as the standard of care during LM PCI. ${ }^{30}$ IVUS guidance in LM PCI is a class IIa ${ }^{17}$ or $\mathrm{IIb}^{16}$ recommendation in the current guidelines.

IVUS has been used to clarify the distribution, burden, and composition of plaque in LM lesions. Complete recognition of these factors is crucial for planning and performing LM PCI. In contrast to angiography findings, IVUS identifies the diffuse nature of plaques involving not only the LM segment but also both flow dividers (left anterior descending artery, LAD and left circumflex artery, LCX). ${ }^{31}$ Continuous plaque from the LM segment into the proximal LAD was seen in $90 \%$ of cases, into the LCX in $66.4 \%$, and into both LAD and LCX in $62 \%$. Additionally, in the setting of distal/ bifurcation LM lesions, the importance of performing IVUS pullbacks from both LAD and LCX has been highlighted. ${ }^{32}$ This is because of the inaccuracy of assessing lumen dimensions of the LCX ostium by IVUS pullback from LAD. IVUS is also critical for the optimization of post-procedural MLA to reduce the restenosis rate. A previous IVUS study showed that post-stenting MLA cutoff values that best predicted instent restenosis on a segment basis were $5.0 \mathrm{~mm}^{2}$ in ostial LCX, $6.3 \mathrm{~mm}^{2}$ in ostial LAD, $7.2 \mathrm{~mm}^{2}$ in polygon of confluence (confluence zone of LAD and LCX), and $8.2 \mathrm{~mm}^{2}$ in LM. Post-stenting underexpansion was an independent predictor for major adverse cardiac events. ${ }^{33}$

There are few appropriately designed studies examining whether IVUS-guided PCI is better than angiography-guided PCI in LM lesions. However, in a post-hoc analysis from the MAIN-COMPARE (revascularization for unprotected LM coronary artery stenosis: comparison of percutaneous coronary angioplasty vs surgical revascularization) registry, the IVUS-guided PCI group showed a lower 3-year cumulative mortality rate than the angiography-guided PCI group for LM lesions ( $4.7 \%$ vs $16 \%, P=0.048)$. Of note, these favorable outcomes were seen exclusively in patients who were treated with DES. ${ }^{34}$ It has been postulated that the benefit of IVUS guidance was associated with a reduced incidence of sudden cardiac death caused by late ST. A recently published study on DES in LM lesions also showed a lower 3-year composite rate of cardiac death, myocardial infarction, and target lesion revascularization (TLR) in the IVUS-guided PCI group compared with the angiography-guided PCI group (11.3\% vs $16.4 \%, P=0.04)$. These trends were more prominent in the subgroup with distal LM lesions ( $10 \%$ vs $19.3 \%, P=0.03) .{ }^{35}$ Therefore, the necessity for meticulous IVUS evaluation in LM PCI is once again emphasized, especially in distal LM lesions. Figure 1 shows a representative case of IVUS-guided LM intervention.

\section{Bifurcation lesions}

Coronary bifurcation PCI represents $10 \%-15 \%$ of PCI procedures. ${ }^{36}$ Although many devices and techniques have been introduced, coronary bifurcation lesions are still a challenging field of interventional cardiology because of the lower procedural success rate and unfavorable clinical outcomes compared with non-bifurcation lesions. ${ }^{37}$ Furthermore, it is difficult to decide on an adequate stent technique and whether to intervene in compromised side branches, both of which depend on many factors including bifurcation anatomy and plaque distribution. ${ }^{38}$ Bifurcation lesions may show dynamic changes during PCI, with plaque/carina shift or dissection leading to side branch compromise and requiring adjustment to the interventional approach. ${ }^{36}$ Therefore, accurate anatomic characterization of bifurcation lesions may improve stent sizing and deployment techniques. After stent deployment, IVUS can detect edge dissection, stent underexpansion, or stent malapposition, which have been strongly associated with future stent failure. Kim et al showed that the 3-year cumulative incidence of death or myocardial infarction was significantly lower in the IVUS-guided PCI group compared to the angiography-guided PCI group for bifurcation lesions (3.8\% vs $7.8 \%, P=0.03) .{ }^{37}$ Two-stent technique and final kissing balloon were more frequently used in the IVUS-guided PCI group. However, most of the patients with bifurcation lesions do not require a two-stent technique and most of the angiographically significant side branches are functionally insignificant. ${ }^{38,39}$ Therefore, unnecessary intervention to side branches might be avoided by meticulous IVUS evaluation, even in true bifurcation lesions. In another study regarding complex bifurcation lesions (nearly $90 \%$ of the lesions were medina class $1,1,1)$, the number of implanted stents was significantly lower in the IVUS-guided PCI group. ${ }^{36}$ Also, the rate of TLR was significantly lower in the IVUS-guided PCI group ( $6 \%$ vs $21 \%, P=0.001)$. In this regard, the role of IVUS in decreasing the TLR rate may become more important in patients with the most complex bifurcation lesions. A decrease in the number of stents in the IVUS-guided PCI group may have reduced the TLR rate. Also in that study, stent underexpansion was found in $27 \%$ of patients in the 


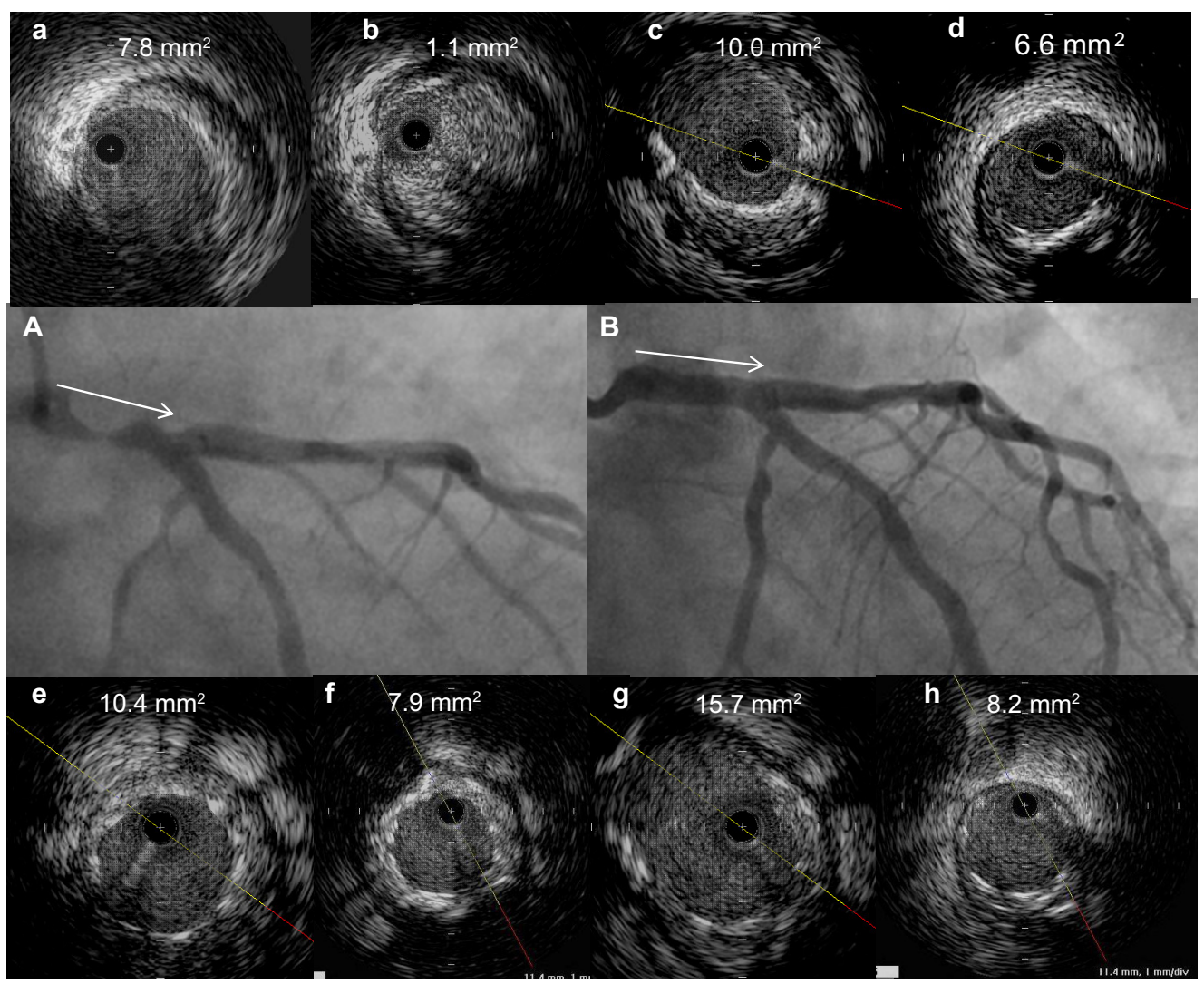

Figure I A 54-year-old male presenting with unstable angina showed significant stenosis of left main coronary artery (LMCA).

Notes: The patient had undergone percutaneous coronary intervention at the LMCA to proximal left anterior descending artery with a sirolimus-eluting stent. (A) Pre-intervention: cross-sectional intravascular ultrasound images from a (proximal) to d (distal) showed attenuated plaque and significant luminal stenosis of LMCA (minimal lumen area: I. I I mm²). (B) Post-intervention: cross-sectional images from e (proximal) to h (distal) showed that the minimal lumen area increased to $7.9 \mathrm{~mm}^{2}$ after intervention. Arrows in (A) and (B) indicate the sequence of intravascular ultrasound images.

IVUS-guided PCI group, and these findings prompted further intervention. ${ }^{36}$ Given the high incidence of stent underexpansion leading to further intervention and lower rates of TLR or ST in the IVUS group, these findings suggest that IVUS might prevent adverse clinical outcomes specifically in patients in whom stent underexpansion is discovered. ${ }^{36}$ Also, avoidance of unnecessary post-dilation to compromise side branches as well as adequate stent expansion without compromising side branches might be the important advantages of using IVUS. ${ }^{37}$ In these contexts, liberal and active use of IVUS in bifurcation PCI is encouraged. Figure 2 shows a representative case of IVUS-guided intervention for bifurcation lesion.

\section{Chronic total occlusions}

Successful PCI of chronic total occlusion (CTO) has been associated with an improvement of angina, left ventricular function, and survival, compared with failed PCI of CTO. ${ }^{40,41}$ However, an increased risk of ST after CTO recanalization with DES has been suggested because of delayed reendothelialization, exposure of deep plaque components, persistence of well-developed collaterals, long stenting, and high incidence of stent malapposition. ${ }^{40}$ Also, CTO lesions show a higher restenosis rate than other lesion subsets, even with DES. ${ }^{42}$ Pre-PCI IVUS can accurately measure the reference vessel diameter and lesion length for appropriate stent sizing when it is difficult for operators to accurately decide stent size with angiography alone, especially in CTO lesions. Post-PCI IVUS may detect PCI complications or suboptimal stent deployment such as stent edge dissection, underexpansion, malapposition, or incomplete lesion coverage, which subsequently necessitate further intervention. ${ }^{40}$ Thus, IVUS could lead to optimal stent deployment with improved clinical outcomes. Hong et al showed that IVUSguided PCI reduced the 2-year cumulative incidence of ST compared with angiography-guided PCI (0\% vs $3.0 \%$, $P=0.014) .{ }^{40}$ Furthermore, in subgroup analysis of TLR, a significant interaction was observed between the use of IVUS and lesion length for predicting TLR $(P=0.037)$, suggesting the usefulness of IVUS in long-lesion $(\geq 30 \mathrm{~mm})$ relative to short-lesion $(<30 \mathrm{~mm}) \mathrm{CTO}$. In a recent CTO study, in-stent late luminal loss at 1-year follow-up was 


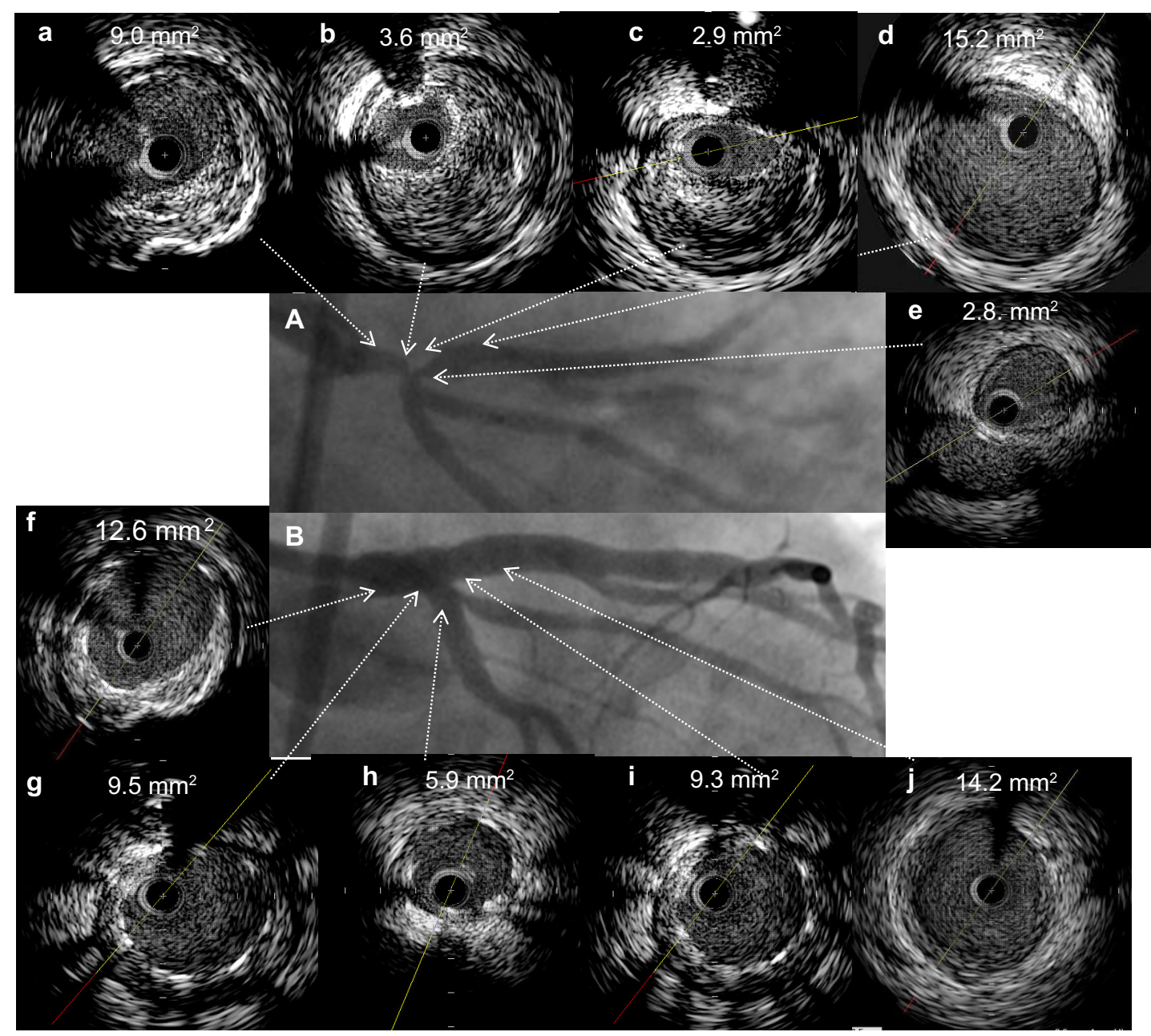

Figure 2 A 62-year-old male presenting with unstable angina showed significant stenosis of distal left main coronary artery (LMCA) bifurcation.

Notes: The patient had undergone percutaneous coronary intervention at LMCA to proximal left anterior descending (LAD) artery and proximal left circumflex artery (LCX) with a crushing stent technique. (A) Pre-intervention: cross-sectional intravascular ultrasound images from a (proximal) to e (distal) showed significant luminal stenosis of distal LMCA bifurcation lesions (minimal lumen area $3.6 \mathrm{~mm}^{2}$ in LMCA, $2.9 \mathrm{~mm}^{2}$ in proximal LAD, and $2.8 \mathrm{~mm}^{2}$ in proximal LCX). (B) Post-intervention: cross-sectional images from $\mathrm{f}$ (proximal) to $\mathrm{j}$ (distal) showed that the minimal lumen area increased to $9.5 \mathrm{~mm}^{2}$ in LMCA, $9.3 \mathrm{~mm}^{2}$ in proximal LAD, and $5.9 \mathrm{~mm}{ }^{2}$ in proximal LCX.

significantly lower in the IVUS-guided group compared with the angiography-guided group $(0.28 \pm 0.48$ vs $0.46 \pm 0.68 \mathrm{~mm}$, $P=0.025$ ), although these angiographic findings were not translated into improved clinical outcomes. ${ }^{43}$ With the enhanced performance of the next-generation DES, clinical outcomes can be more importantly attributed to procedural factors. Thus, optimization of stent implantation with IVUS guidance could be important for the next-generation DES. ${ }^{40}$ Another advantage of IVUS in CTO lesions might be its ability to assist in antegrade or retrograde recanalization of the CTO segment. CTO recanalization with a guide wire is the most important and difficult step in CTO intervention. IVUS can give information about the exact location of the guide wire (ie, true lumen vs subintima) and help find the entry point of the occlusion. Even when the guide wire enters into the subintimal space, IVUS may facilitate the discovery of the true lumen. ${ }^{3}$ Moreover, IVUS has been successfully used during more complex retrograde approaches in which the lesion is approached from both directions and a balloon is advanced over the antegrade wire and inflated within the subintimal space, permitting the IVUS catheter to be advanced and positioned subintimally. Under IVUS guidance, the retrograde wire can then be manipulated from the subintimal space into the true lumen and beyond the occluded segment. ${ }^{3}$ It should be noted that a lot of experience is needed to correctly interpret IVUS images. ${ }^{44,45}$ In general, however, IVUS-guided PCI is recommended in CTO lesions.

\section{Long lesions}

A long lesion itself inevitably increases the stent length, and long stent increases the incidence of stent malapposition or underexpansion. Stent malapposition or underexpansion is 
a well-known risk factor for future stent failure. Therefore, performing PCI for long lesions can be problematic, and the rate of ST may be higher in this lesion subset. ${ }^{11,46}$ IVUS can provide useful information about the status of a long stent that can lead to stent optimization and overcome the potential deleterious effect of long lesions. Therefore, IVUS-guided PCI in long lesions is expected to decrease the incidence of adverse clinical events. In a multicenter randomized study involving 543 patients treated with stent length $\geq 28 \mathrm{~mm}$, IVUS guidance did not improve the clinical outcomes (1-year composite rate of cardiovascular death, myocardial infarction, target vessel revascularization, and ST) compared to angiographic guidance $(4.5 \%$ vs $7.3 \%, P=0.16$ in intention to treat analysis). ${ }^{11}$ However, when per protocol analysis was applied, the benefits of IVUS were significant (4.0\% vs $8.1 \%, P=0.048)$. This discrepancy may be explained by the insufficient sample size and considerable crossover rate. Therefore, a larger scale prospective study (impact of IVUS guidance on long-term clinical outcomes of everolimus-eluting stents in long coronary lesions) is currently underway to establish the effect of the IVUS guidance in long-lesion PCI.

\section{Calcified lesions}

Clinical factors associated with calcified lesions include increased patient age, male sex, hypertension, diabetes, stable (vs unstable) angina, and renal function, especially the need for hemodialysis. ${ }^{47}$ Calcium is assessed quantitatively with IVUS according to the arc and length. Calcium is described qualitatively according to its location: lesion vs reference and superficial vs deep (leading edge of the acoustic shadow within the deepest $50 \%$ of the plaque and media thickness). There is general agreement that the greater the arc, length, or thickness of calcium on IVUS, the greater the likelihood of stent underexpansion and malapposition that can be associated with adverse events, including restenosis and ST. ${ }^{35,48,49}$ In the setting of severe calcification, iterative IVUS imaging in conjunction with repeated high-pressure balloon inflations can be used to optimize stent expansion and apposition. Furthermore, lesion preparation with a cutting/ scoring balloon or rotational atherectomy can be used to optimize stent implantation in a way not possible using angiography alone. ${ }^{47}$

\section{In-stent restenosis}

In-stent restenosis remains one of the main problems after metallic stent implantation. The process of restenosis is complex, and there are many factors that can influence the neointimal proliferation process within the stented segment: procedure-related factors such as stent underexpansion or traumatic injury of vessel wall at stent edges; stent-related mechanical factors such as stent fractures or damaged polymers; and biological factors such as drug resistance. ${ }^{3}$ In PCI for in-stent restenosis, IVUS can assist in the differentiation of restenosis that is related predominantly to intimal hyperplasia vs mechanical complications, such as stent fracture or underexpansion. ${ }^{5}$ IVUS-guided high-pressure angioplasty with a noncompliant balloon is often performed when stent underexpansion is the major mechanism for restenosis to avoid the deployment of a second stent. Balloon-alone angioplasty may also be appropriate in the presence of very focal lesions caused by neointimal hyperplasia. In patients with diffuse or proliferative in-stent restenosis, a second DES is often warranted. ${ }^{5}$ The use of IVUS to guide PCI in patients with restenosis is a class IIa recommendation in the current PCI guidelines. ${ }^{16,17}$ Figure 3 shows a representative case of IVUS-guided intervention in stented lesions with significant stenosis.

\section{Future perspectives Optical coherence tomography}

Although IVUS is the most widely used intracoronary imaging modality in interventional cardiology, it is used in fewer than $20 \%$ of PCI procedures. ${ }^{6}$ As intracoronary imaging is increasingly focusing on plaque/neointima characterization and neointimal coverage of the stent, the relatively low resolution of IVUS (100-150 $\mu \mathrm{m})$ becomes a weakness. Intracoronary optical coherence tomography (OCT) has emerged as an attractive new imaging modality with superior resolution $(10-15 \mu \mathrm{m}){ }^{50}$ It offers a clear view around the vessel lumen or stent edges and in vivo plaque/neointima evaluation. ${ }^{6}$ However, OCT cannot consistently visualize external elastic membrane because of its shallow penetration depth (1-2 mm), and thus cannot measure vessel size or plaque burden with confidence. Several studies have also reported that lumen dimensions measured by OCT were smaller than those measured by IVUS. ${ }^{50-52}$ In a previous study comparing IVUS and OCT measurements (listed in Table 3), the lumen areas measured by OCT were much smaller than those measured by IVUS (mean difference, 1.11-1.67 $\mathrm{mm}^{2}$ ). ${ }^{53}$ These differences in measurements between OCT and IVUS may decrease the size or deployment pressure of the stent and adjuvant balloon in OCT-guided PCI, which could lead to stent underexpansion. ${ }^{54}$ The paradigm of IVUS guidance for stent optimization that has developed over the past 2 decades does not translate directly to OCT. ${ }^{6}$ Moreover, although OCT has much higher resolution and adds more information, it is not 


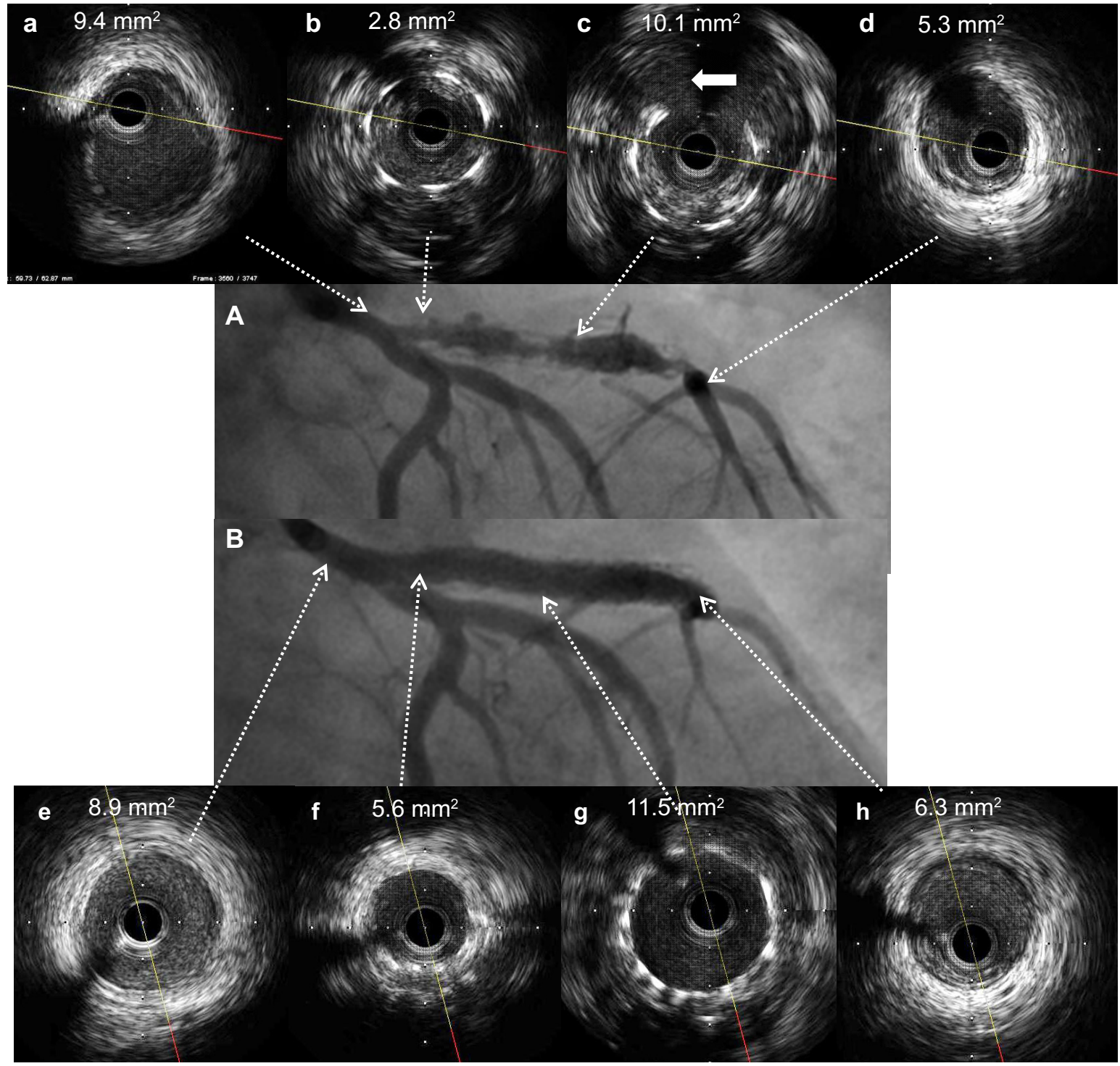

Figure 3 A 60-year-old patient presenting with acute myocardial infarction had a history of drug-eluting stent (sirolimus-eluting stent $3.5 \times 33$ mm) implantation in the proximal left anterior descending (LAD) artery 6 years previously.

Notes: Emergency coronary angiography revealed significant narrowing in the previously stented segment at proximal LAD, suggestive of very late stent thrombosis. (A) Pre-intervention: cross-sectional intravascular ultrasound images from a (proximal) to $\mathrm{d}$ (distal) showed neointimal hyperplasia with aneurysm formation (white arrow in c). (B) Post-intervention coronary angiogram of the previously stented segment: cross-sectional images from e (proximal) to h (distal) after stent implantation.

Table 3 Comparison between IVUS and OCT measurements

\begin{tabular}{|c|c|c|c|c|c|}
\hline Study & $\mathbf{N}$ & Study protocol & IVUS measurements & OCT measurements & $P$-value \\
\hline \multirow[t]{2}{*}{ Yamaguchi et al ${ }^{50}$} & 76 & IVUS vs OCT measurements & MLD $2.3 \pm 0.6 \mathrm{~mm}$ & MLD $2.2 \pm 0.7 \mathrm{~mm}$ & $P=0.008$ \\
\hline & & in the same native vessel & MLA $5.6 \pm 2.6 \mathrm{~mm}^{2}$ & MLA $5.2 \pm 2.8 \mathrm{~mm}^{2}$ & $P<0.00 I$ \\
\hline \multirow[t]{2}{*}{ Okamura et al $\left.\right|^{51}$} & 19 & IVUS vs OCT measurements & Minimum stent area & Minimum stent area & Not significant \\
\hline & & in the same native vessel & $6.26 \pm 2.01 \mathrm{~mm}^{2}$ & $5.84 \pm 1.89 \mathrm{~mm}^{2}$ & \\
\hline \multirow[t]{2}{*}{ Bezerra et $\mathrm{a}^{52}$} & 100 & $\begin{array}{l}\text { IVUS vs OCT measurements } \\
\text { in the same native vessel }\end{array}$ & MLA $3.32 \pm 1.92 \mathrm{~mm}^{2}$ & MLA $2.33 \pm 1.56 \mathrm{~mm}^{2}$ & $P<0.00 I$ \\
\hline & & & IVUS-guided PCI & OCT-guided PCI & \\
\hline \multirow[t]{2}{*}{ Habara et $\mathrm{a}^{54}$} & 70 & IVUS-guided $\mathrm{PCI}$ vs & Minimum stent area $7.1 \pm 2.1 \mathrm{~mm}^{2}$ & Minimum stent area $6.1 \pm 2.2 \mathrm{~mm}^{2}$ & $P=0.04$ \\
\hline & & OCT-guided PCl & Mean stent area $8.7 \pm 2.4 \mathrm{~mm}^{2}$ & Mean stent area $7.5 \pm 2.5 \mathrm{~mm}^{2}$ & $P=0.04$ \\
\hline
\end{tabular}

Abbreviations: IVUS, intravascular ultrasound; OCT, optical coherence tomography; MLD, minimum luminal diameter; MLA, minimum luminal area; PCI, percutaneous coronary intervention. 
clear whether this additional information improves clinical outcomes. Because OCT, like IVUS, evaluates anatomic dimensions rather than functional significance, its use in assessing lesion physiology will be limited. ${ }^{4}$ Nevertheless, with its enhanced resolution it is expected that OCT will be a useful imaging tool to guide PCI.

\section{Culprit lesion and vulnerable plaque}

In patients with acute coronary syndrome, plaque rupture occurs in $60 \%-65 \%$ of cases, plaque erosion in $30 \%-35 \%$, and a calcified nodule in $5 \% .{ }^{48}$ The final common pathway is thrombus formation. Although the culprit lesion is sometimes evident, some patients have either no identifiable culprit lesion, or multiple potential culprit lesions. IVUS detects plaque rupture in approximately one-half of STsegment elevation myocardial infarction culprit lesions. ${ }^{55,56}$ However, the superior resolution and obligatory flushing with OCT can sharply outline the vascular lumen area, and thus optimize identification of ruptured plaques. ${ }^{48}$

The precursor of the ruptured thrombotic plaque is the thin-cap fibroatheroma, the most common type of vulnerable plaque. To date, only virtual-histology (VH)-IVUS has been shown to predict future events. ${ }^{48}$ VH-IVUS is based on spectral analysis of radiofrequency data acquired with IVUS catheters and uses these results to identify four different tissue types: fibrous tissue, fibrofatty tissue, necrotic core, and dense calcium. ${ }^{3}$ In the PROSPECT study, predictors of non-culprit future events at 3 years were a thin-cap fibroatheroma on VH-IVUS, IVUS MLA $<4.0 \mathrm{~mm}^{2}$, and IVUS plaque burden $>70 \% .{ }^{57}$ Although VH-IVUS can only infer the presence of the thin-cap fibroatheroma by the presence of a necrotic core abutting the lumen, OCT is able to identify many features, including fibrous cap thickness, macrophages in the fibrous cap, and an underlying lipid core. ${ }^{48}$ The appropriateness of routine invasive imaging to screen for vulnerable plaques and stenting of these vulnerable plaques is a current subject of debate.

\section{Future direction of intracoronary imaging}

The introduction of IVUS has significantly increased our knowledge and the understanding of balloon angioplasty, stent implantation, and stent failure. IVUS has been established as the most validated and reliable intracoronary imaging modality to guide PCI in angiographic intermediate lesions and complex lesions. Until other intracoronary imaging techniques such as OCT can validate lumen measurements for optimal stent deployment and demonstrate improvement in clinical outcomes, IVUS will remain the first choice to guide PCI. ${ }^{6}$ High-frequency IVUS catheters that are under investigation may provide better resolution than the current version of IVUS. ${ }^{58}$ Other imaging modalities, such as near-infrared spectroscopy, have also been developed to detect lipid composition. In addition, forward-looking IVUS systems are under investigation, and may assist in CTO intervention. ${ }^{5,59}$ However, the future of intravascular imaging may be the integration of functional and anatomical assessment (ie, a combined IVUS and FFR catheter). ${ }^{19}$ Currently available imaging modalities have their own advantages and disadvantages, and thus, they are complementary rather than competitive with one another. Therefore, a combined catheter that integrates two or more modalities and allows real-time coregistration of images acquired from different transducers will certainly attract clinical attention. ${ }^{3}$ Dual-modality imaging probes combining IVUS and OCT have been shown to be feasible in several studies. ${ }^{60}$ A combined near-infrared spectroscopy and IVUS catheter has been developed and introduced for clinical use. ${ }^{61}$ Combined information obtained from these catheters would be very helpful for enhancing PCI quality, and ultimately improving clinical outcomes. Besides this technological progress, patients are becoming older, and the diabetic problem is getting larger worldwide, both of which will result in more complex coronary lesions and increased PCI. Intracoronary imaging has been proven to be a useful asset in complex coronary intervention, and will remain so for many years to come in the predicted future patient population. ${ }^{3}$

\section{Conclusion}

IVUS provides valuable anatomic information about the coronary vessel lumen, wall, and plaque. However, IVUS should be used cautiously for physiologic assessment of angiographic intermediate lesions. IVUS and FFR are complementary techniques that can guide decision-making for these lesions. In complex coronary lesions, IVUS is useful for accurate lesion assessment, stent optimization, and detection of complications. Therefore, it can reduce the rate of stent failure and improve clinical outcomes in such lesions. IVUS can also help to identify culprit lesions and vulnerable plaques. Newer imaging modalities with higher resolution (such as OCT) are increasingly being used to guide coronary intervention. However, these new devices need to be validated and show an acceptable improvement in clinical outcomes. Until then, IVUS will remain the most validated tool, and the first choice for guiding PCI. 


\section{Acknowledgments}

This study was supported by a grant from the Korea Healthcare Technology R\&D Project, Ministry for Health, Welfare and Family Affairs, Republic of Korea (Nos A085136 and A102064) and the Cardiovascular Research Center, Seoul, Korea.

\section{Disclosure}

The authors report no conflicts of interest in this work.

\section{References}

1. Waller BF, Pinkerton CA, Slack JD. Intravascular ultrasound: a histological study of vessels during life. The new 'gold standard' for vascular imaging. Circulation. 1992;85(6):2305-2310.

2. Nissen SE, Yock P. Intravascular ultrasound: novel pathophysiological insights and current clinical applications. Circulation. 2001;103(4): 604-616.

3. Nakatani S, Proniewska K, Pociask E, et al. How clinically effective is intravascular ultrasound in interventional cardiology? Present and future perspectives. Expert Rev Med Devices. 2013;10(6):735-749.

4. Lotfi A, Jeremias A, Fearon WF, et al. Expert consensus statement on the use of fractional flow reserve, intravascular ultrasound, and optical coherence tomography: a consensus statement of the Society of Cardiovascular Angiography and Interventions. Catheter Cardiovasc Interv. 2014;83(4):509-518.

5. McDaniel MC, Eshtehardi P, Sawaya FJ, Douglas JS Jr, Samady H. Contemporary clinical applications of coronary intravascular ultrasound. JACC Cardiovasc Interv. 2011;4(11):1155-1167.

6. Waksman R, Kitabata H, Prati F, Albertucci M, Mintz GS. Intravascular ultrasound versus optical coherence tomography guidance. $J$ Am Coll Cardiol. 2013;62(17 Suppl):S32-S40.

7. Witzenbichler B, Maehara A, Weisz G, et al. Relationship between intravascular ultrasound guidance and clinical outcomes after drug-eluting stents: the assessment of dual antiplatelet therapy with drug-eluting stents (ADAPT-DES) study. Circulation. 2014;129(4):463-470.

8. Jang JS, Song YJ, Kang W, et al. Intravascular ultrasound-guided implantation of drug-eluting stents to improve outcome: a meta-analysis. JACC Cardiovasc Interv. 2014;7(3):233-243.

9. Ahn JM, Kang SJ, Yoon SH, et al. Meta-analysis of outcomes after intravascular ultrasound-guided versus angiography-guided drugeluting stent implantation in 26,503 patients enrolled in three randomized trials and 14 observational studies. Am J Cardiol. 2014;113(8): 1338-1347.

10. Roy P, Steinberg DH, Sushinsky SJ, et al. The potential clinical utility of intravascular ultrasound guidance in patients undergoing percutaneous coronary intervention with drug-eluting stents. Eur Heart $J$. 2008;29(15):1851-1857.

11. Kim JS, Kang TS, Mintz GS, et al. Randomized comparison of clinical outcomes between intravascular ultrasound and angiography-guided drug-eluting stent implantation for long coronary artery stenoses. JACC Cardiovasc Interv. 2013;6(4):369-376.

12. Jakabcin J, Spacek R, Bystron M, et al. Long-term health outcome and mortality evaluation after invasive coronary treatment using drug eluting stents with or without the IVUS guidance. Randomized control trial. HOME DES IVUS. Catheter Cardiovasc Interv. 2010;75(4):578-583.

13. Park KW, Kang SH, Yang HM, et al. Impact of intravascular ultrasound guidance in routine percutaneous coronary intervention for conventional lesions: data from the EXCELLENT trial. Int J Cardiol. 2013;167(3): 721-726.

14. Youn YJ, Yoon J, Lee JW, et al. Intravascular ultrasound-guided primary percutaneous coronary intervention with drug-eluting stent implantation in patients with ST-segment elevation myocardial infarction. Clin Cardiol. 2011;34(11):706-713.
15. Chieffo A, Latib A, Caussin C, et al. A prospective, randomized trial of intravascular-ultrasound guided compared to angiography guided stent implantation in complex coronary lesions: the AVIO trial. Am Heart J. 2013;165(1):65-72.

16. Levine GN, Bates ER, Blankenship JC, et al. 2011 ACCF/AHA/ SCAI Guideline for Percutaneous Coronary Intervention. A report of the American College of Cardiology Foundation/American Heart Association Task Force on Practice Guidelines and the Society for Cardiovascular Angiography and Interventions. $\mathrm{J} \mathrm{Am} \mathrm{Coll} \mathrm{Cardiol.}$ 2011;58(24):e44-e122.

17. Windecker S, Kolh P, Alfonso F, et al. 2014 ESC/EACTS Guidelines on myocardial revascularization: the Task Force on Myocardial Revascularization of the European Society of Cardiology (ESC) and the European Association for Cardio-Thoracic Surgery (EACTS) Developed with the special contribution of the European Association of Percutaneous Cardiovascular Interventions (EAPCI). Eur Heart J. 2014;35(37):2541-2619.

18. Pijls NH, Tanaka N, Fearon WF. Functional assessment of coronary stenoses: can we live without it? Eur Heart J. 2013;34(18):1335-1344.

19. Jegere S, Narbute I, Erglis A. Use of intravascular imaging in managing coronary artery disease. World J Cardiol. 2014;6(6):393-404.

20. Jasti V, Ivan E, Yalamanchili V, Wongpraparut N, Leesar MA. Correlations between fractional flow reserve and intravascular ultrasound in patients with an ambiguous left main coronary artery stenosis. Circulation. 2004;110(18):2831-2836.

21. de la Torre Hernandez JM, Hernandez Hernandez F, Alfonso F, et al. Prospective application of pre-defined intravascular ultrasound criteria for assessment of intermediate left main coronary artery lesions results from the multicenter LITRO study. J Am Coll Cardiol. 2011;58(4):351-358.

22. Park SJ, Ahn JM, Kang SJ, et al. Intravascular ultrasound-derived minimal lumen area criteria for functionally significant left main coronary artery stenosis. JACC Cardiovasc Interv. 2014;7(8):868-874.

23. Kang SJ, Lee JY, Ahn JM, et al. Intravascular ultrasound-derived predictors for fractional flow reserve in intermediate left main disease. JACC Cardiovasc Interv. 2011;4(11):1168-1174.

24. Pijls NH, Sels JW. Functional measurement of coronary stenosis. J Am Coll Cardiol. 2012;59(12):1045-1057.

25. Kang SJ, Lee JY, Ahn JM, et al. Validation of intravascular ultrasoundderived parameters with fractional flow reserve for assessment of coronary stenosis severity. Circ Cardiovasc Interv. 2011;4(1):65-71.

26. Briguori C, Anzuini A, Airoldi F, et al. Intravascular ultrasound criteria for the assessment of the functional significance of intermediate coronary artery stenoses and comparison with fractional flow reserve. Am J Cardiol. 2001;87(2):136-141.

27. Lee CH, Tai BC, Soon CY, et al. New set of intravascular ultrasoundderived anatomic criteria for defining functionally significant stenoses in small coronary arteries (results from Intravascular Ultrasound Diagnostic Evaluation of Atherosclerosis in Singapore [IDEAS] study). Am J Cardiol. 2010;105(10):1378-1384.

28. Waksman R, Legutko J, Singh J, et al. FIRST: Fractional Flow Reserve and Intravascular Ultrasound Relationship Study. J Am Coll Cardiol. 2013;61(9):917-923.

29. Takayama T, Hodgson JM. Prediction of the physiologic severity of coronary lesions using 3D IVUS: validation by direct coronary pressure measurements. Catheter Cardiovasc Interv. 2001;53(1):48-55.

30. Puri R, Kapadia SR, Nicholls SJ, Harvey JE, Kataoka Y, Tuzcu EM. Optimizing outcomes during left main percutaneous coronary intervention with intravascular ultrasound and fractional flow reserve: the current state of evidence. JACC Cardiovasc Interv. 2012;5(7): 697-707.

31. Oviedo C, Maehara A, Mintz GS, et al. Intravascular ultrasound classification of plaque distribution in left main coronary artery bifurcations: where is the plaque really located? Circ Cardiovasc Interv. 2010;3(2): 105-112.

32. Oviedo C, Maehara A, Mintz GS, et al. Is accurate intravascular ultrasound evaluation of the left circumflex ostium from a left anterior descending to left main pullback possible? Am J Cardiol. 2010;105(7): 948-954. 
33. Kang SJ, Ahn JM, Song H, et al. Comprehensive intravascular ultrasound assessment of stent area and its impact on restenosis and adverse cardiac events in 403 patients with unprotected left main disease. Circ Cardiovasc Interv. 2011;4(6):562-569.

34. Park SJ, Kim YH, Park DW, et al. Impact of intravascular ultrasound guidance on long-term mortality in stenting for unprotected left main coronary artery stenosis. Circ Cardiovasc Interv. 2009;2(3): 167-177.

35. de la Torre Hernandez JM, Baz Alonso JA, Gomez Hospital JA, et al. Clinical impact of intravascular ultrasound guidance in drug-eluting stent implantation for unprotected left main coronary disease: pooled analysis at the patient-level of 4 registries. JACC Cardiovasc Interv. 2014;7(3):244-254.

36. Patel Y, Depta JP, Novak E, et al. Long-term outcomes with use of intravascular ultrasound for the treatment of coronary bifurcation lesions. Am J Cardiol. 2012;109(7):960-965.

37. Kim JS, Hong MK, Ko YG, et al. Impact of intravascular ultrasound guidance on long-term clinical outcomes in patients treated with drugeluting stent for bifurcation lesions: data from a Korean multicenter bifurcation registry. Am Heart J. 2011;161(1):180-187.

38. Latib A, Colombo A. Bifurcation disease: what do we know, what should we do? JACC Cardiovasc Interv. 2008;1(3):218-226.

39. Koo BK, Kang HJ, Youn TJ, et al. Physiologic assessment of jailed side branch lesions using fractional flow reserve. J Am Coll Cardiol. 2005;46(4):633-637.

40. Hong SJ, Kim BK, Shin DH, et al. Usefulness of intravascular ultrasound guidance in percutaneous coronary intervention with secondgeneration drug-eluting stents for chronic total occlusions (from the Multicenter Korean-Chronic Total Occlusion Registry). Am J Cardiol. 2014;114(4):534-540.

41. Jones DA, Weerackody R, Rathod K, et al. Successful recanalization of chronic total occlusions is associated with improved long-term survival. JACC Cardiovasc Interv. 2012;5(4):380-388.

42. Kastrati A, Dibra A, Mehilli J, et al. Predictive factors of restenosis after coronary implantation of sirolimus- or paclitaxel-eluting stents. Circulation. 2006;113(19):2293-2300.

43. Tian NL, Gami SK, Ye F, et al. Angiographic and clinical comparisons of intravascular ultrasound- versus angiography-guided drug-eluting stent implantation for patients with chronic total occlusion lesions: two-year results from a randomised AIR-CTO study. EuroIntervention. 2015;10(12):1409-1417.

44. Park Y, Park HS, Jang GL, et al. Intravascular ultrasound guided recanalization of stumpless chronic total occlusion. Int J Cardiol. 2011;148(2):174-178.

45. Rathore S, Katoh O, Tuschikane E, Oida A, Suzuki T, Takase S. A novel modification of the retrograde approach for the recanalization of chronic total occlusion of the coronary arteries intravascular ultrasound-guided reverse controlled antegrade and retrograde tracking. JACC Cardiovasc Interv. 2010;3(2):155-164.

46. Kimura T, Morimoto T, Nakagawa Y, et al. Very late stent thrombosis and late target lesion revascularization after sirolimus-eluting stent implantation: five-year outcome of the j-Cypher Registry. Circulation. 2012;125(4):584-591.
47. Mintz GS. Intravascular imaging of coronary calcification and its clinical implications. JACC Cardiovasc Imaging. 2015;8(4):461-471.

48. Mintz GS. Clinical utility of intravascular imaging and physiology in coronary artery disease. J Am Coll Cardiol. 2014;64(2):207-222.

49. Hassan AK, Bergheanu SC, Stijnen T, et al. Late stent malapposition risk is higher after drug-eluting stent compared with bare-metal stent implantation and associates with late stent thrombosis. Eur Heart J. 2010;31(10):1172-1180.

50. Yamaguchi T, Terashima M, Akasaka T, et al. Safety and feasibility of an intravascular optical coherence tomography image wire system in the clinical setting. Am J Cardiol. 2008;101(5):562-567.

51. Okamura T, Onuma Y, Garcia-Garcia HM, et al. First-in-man evaluation of intravascular optical frequency domain imaging (OFDI) of Terumo: a comparison with intravascular ultrasound and quantitative coronary angiography. EuroIntervention. 2011;6(9):1037-1045.

52. Bezerra HG, Attizzani GF, Sirbu V, et al. Optical coherence tomography versus intravascular ultrasound to evaluate coronary artery disease and percutaneous coronary intervention. JACC Cardiovasc Interv. 2013;6(3):228-236.

53. Gonzalo N, Serruys PW, Garcia-Garcia HM, et al. Quantitative ex vivo and in vivo comparison of lumen dimensions measured by optical coherence tomography and intravascular ultrasound in human coronary arteries. Rev Esp Cardiol. 2009;62(6):615-624.

54. Habara M, Nasu K, Terashima M, et al. Impact of frequency-domain optical coherence tomography guidance for optimal coronary stent implantation in comparison with intravascular ultrasound guidance. Circ Cardiovasc Interv. 2012;5(2):193-201.

55. Kubo T, Imanishi T, Takarada S, et al. Assessment of culprit lesion morphology in acute myocardial infarction: ability of optical coherence tomography compared with intravascular ultrasound and coronary angioscopy. J Am Coll Cardiol. 2007;50(10):933-939.

56. Hong MK, Mintz GS, Lee CW, et al. Comparison of coronary plaque rupture between stable angina and acute myocardial infarction: a three-vessel intravascular ultrasound study in 235 patients. Circulation. 2004;110(8):928-933.

57. Stone GW, Maehara A, Lansky AJ, et al. A prospective naturalhistory study of coronary atherosclerosis. N Engl J Med. 2011;364(3): 226-235.

58. Li X, Wu W, Chung Y, et al. 80-MHz intravascular ultrasound transducer using PMN-PT free-standing film. IEEE Trans Ultrason Ferroelectr Freq Control. 2011;58(11):2281-2288.

59. Degertekin FL, Guldiken RO, Karaman M. Annular-ring CMUT arrays for forward-looking IVUS: transducer characterization and imaging. IEEE Trans Ultrason Ferroelectr Freq Control. 2006;53(2):474-482.

60. Li BH, Leung AS, Soong A, et al. Hybrid intravascular ultrasound and optical coherence tomography catheter for imaging of coronary atherosclerosis. Catheter Cardiovasc Interv. 2013;81(3):494-507.

61. Garg S, Serruys PW, van der Ent M, et al. First use in patients of a combined near infra-red spectroscopy and intra-vascular ultrasound catheter to identify composition and structure of coronary plaque. EuroIntervention. 2010;5(6):755-756.
Journal of Vascular Diagnostics

\section{Publish your work in this journal}

Journal of Vascular Diagnostics is an international, peer-reviewed journal of diagnostics, focusing on non invasive vascular investigation methods involved in the evaluation of vascular diseases. The journal is committed to the rapid publication in the fields of vascular diseases Original research, review, case reports, expert opinion and commentaries

\section{Dovepress}

are all considered for publication. The manuscript management system is completely online and includes a very quick and fair peer-review system, which is all easy to use. Visit http://www.dovepress.com/ testimonials.php to read real quotes from published authors. 